\title{
Estudo retrospectivo da leucose enzoótica bovina no estado de São Paulo
}

Adriana Hellmeister de Campos Nogueira ${ }^{\left.[]^{[}\right]}$, Vera Cláudia Magalhães Curci[ ${ }^{[b]}$, Priscilla Schoeps Felicio ${ }^{[a]}$, Liria Hiromi Okuda ${ }^{[a]}$, Eliana De Stefano ${ }^{[a]}$, Edviges Maristela Pituco ${ }^{[a]}$

\footnotetext{
[a] Instituto Biológico, Laboratório de Viroses de Bovídeos, Agência Paulista de Tecnologia dos Agronegócios (APTA), Secretaria de Agricultura e Abastecimento do Estado de São Paulo (SAA), São Paulo, SP, Brasil

[b] Unidade de Pesquisa e Desenvolvimento de Araçatuba, APTA, SAA, Araçatuba, SP, Brasil
}

*Autor correspondente

e-mail: adriananogueira@biologico.sp.gov.br

\section{Resumo}

O vírus da leucose bovina (BLV) é o agente causal da leucose enzoótica bovina, responsável por causar importantes perdas econômicas, como redução da eficiência produtiva, tanto na produção de leite e carne como é incluída em alguns protocolos sanitários para exportação de bovinos, sêmen e embriões de países que mantêm programas de controle desta doença. Como a infecção por BLV em bovinos é por toda vida, a demonstração de anticorpos séricos contra BLV indica infecção persistente. Considerando sua importância econômica e prejuízos ao produtor, objetivou-se verificar a ocorrência de anticorpos contra a leucose bovina no estado de São Paulo, utilizando o banco de soros de fêmeas bovinas e as informações epidemiológicas do inquérito epidemiológico da brucelose bovina, delineado para atender o Programa Nacional de Controle e Erradicação da Brucelose e Tuberculose, realizado no estado de São Paulo, no período de 2010 a 2011 . 0 estado de São Paulo foi estratificado em sete circuitos produtores de bovinos, levando-se em consideração os diferentes sistemas de criação e exploração, além da capacidade operacional e logística do serviço veterinário oficial do estado, baseando-se na área de atuação de suas 40 unidades regionais (EDAs). Sorteio aleatório foi realizado selecionando-se um animal de cada uma das 1.283 propriedades amostradas. Para a detecção de anticorpos anti-BLV foi utilizada a técnica de IDGA (Tecpar $\left.{ }^{\circledR}\right)$, sendo encontrada frequência de 14,3\% (184/1283) de bovinos reagentes para BLV. As taxas de ocorrência de BLV obtidos no Brasil variam de $9,0 \%$ a $54 \%$, dependendo do tipo de rebanho e sistema de criação. Sabe-se que a principal forma de transmissão é a iatrogênica, porém, transmissão transplacentária deve ser avaliada, mesmo não sendo considerada uma doença da reprodução, além da necessidade de avaliar o risco de transmissão pelo sêmen ou embrião. Os resultados obtidos no presente estudo indicam presença do BLV nos rebanhos bovinos paulistas e apontam para a necessidade de medidas de controle para esta enfermidade. 